\title{
Lusioersily
}

\section{Infographic. The effects of frequency, intensity, duration and volume of walking interventions on CVD risk factors: a systematic review and meta-regression analysis of randomised controlled trials among inactive healthy adults}

\author{
Oja, P., Williamson, C., Kelly, P., Murtagh, E., Murphy, M. H., Foster, C., \& Titze, S. (2019). Infographic. The \\ effects of frequency, intensity, duration and volume of walking interventions on CVD risk factors: a systematic \\ review and meta-regression analysis of randomised controlled trials among inactive healthy adults. British \\ Journal of Sports Medicine, 53(21), 1379-1380. https://doi.org/10.1136/bjsports-2018-100290
}

Link to publication record in Ulster University Research Portal

Published in:

British Journal of Sports Medicine

Publication Status:

Published (in print/issue): 21/10/2019

DOI:

10.1136/bjsports-2018-100290

\section{Document Version}

Author Accepted version

\section{General rights}

Copyright for the publications made accessible via Ulster University's Research Portal is retained by the author(s) and / or other copyright owners and it is a condition of accessing these publications that users recognise and abide by the legal requirements associated with these rights.

\section{Take down policy}

The Research Portal is Ulster University's institutional repository that provides access to Ulster's research outputs. Every effort has been made to ensure that content in the Research Portal does not infringe any person's rights, or applicable UK laws. If you discover content in the Research Portal that you believe breaches copyright or violates any law, please contact pure-support@ulster.ac.uk. 
The effects of frequency, intensity, duration and volume of walking interventions on CVD risk factors: A systematic review and meta-regression analysis of randomized controlled trials among inactive healthy adults

Pekka Oja, Paul Kelly, Elaine Murtagh, Marie Murphy, Charlie Foster, Sylvia Titze

Corresponding author: Pekka Oja

UKK Institute, P.O.Box 30, 33501 Tampere, Finland

pekka.oja@uta.fi

phone: $+358-503394593$

Other authors:

Paul Kelly: Physical Activity for Health Research Centre, Institute of Sport, Physical Education and Health Sciences, University of Edinburgh, Edinburgh, UK

Elaine Murtagh: Department of Arts Education and Physical Education, Mary Immaculate College, Limerick, Ireland

Marie Murphy: Centre for Physical Activity and Health Research, Ulster University, Belfast, UK

Charlie Foster: Centre for Exercise, Nutrition \& Health Sciences, Bristol University, Bristol, UK

Sylvia Titze: Institute of Sport Sciences, University of Graz, Graz, Austria

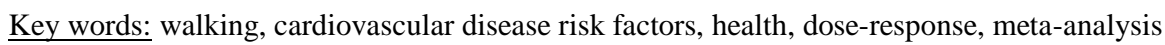

Word count: abstract 250, main text $\mathrm{xxxx}$ (without tables and references)

61 references, 4 tables, 3 supplementary tables, supplementary file, 1 figure 


\title{
The effects of frequency, intensity, duration and volume of walking interventions on CVD risk factors: A systematic review and meta-regression analysis of randomized controlled trials among inactive healthy adults
}

\author{
Pekka Oja, Paul Kelly, Elaine Murtagh, Marie Murphy, Charlie Foster, Sylvia Titze
}

Abstract

Objective. Walking interventions in healthy populations show clinically relevant improvements for many cardiovascular disease (CVD) risk factors. We aimed to assess the changes in CVD risk factors and the dose-response relationship between frequency, intensity, duration and volume of walking based on randomized controlled trials (RCTs).

Design. A systematic review with meta-analysis and meta-regression.

Data sources. Four electronic databases searched from January 1971 to April 2017.

Eligibility criteria. Walking RCTs reporting one or more CVD risk factor outcomes; trials including at least one group with walking intervention and a no-walking control group; duration $\geq 8$ weeks; participants $\geq 18$ years old, inactive but healthy; risk factors assessed pre- and post-intervention; English language articles in peer-reviewed journals.

Results. Thirty-seven RCTs, involving 2001 participants (81\% women), and assessing 13 CVD risk factors were identified. Pooled meta-analysis showed favorable effects $(p \leq 0.05)$ of walking intervention for seven CVD risk factors (body mass, BMI, body fat, systolic and diastolic blood pressure, and fasting glucose, and $\left.\mathrm{VO}_{2} \max \right)$. There were no significant effects $(\mathrm{p}>0.05)$ for waist circumference, waist-to-hip ratio, and four blood lipid variables.

Despite testing 91 possible dose-response relationships, linear meta-regression analysis adjusted for age indicated just 7 (or $7.7 \%$ ) statistically significant findings.

Summary/conclusion. Walking interventions benefit a number of CVD risk factors. Despite multiple studies and tested metrics only a few dose-response relationships were identified and the possibility of chance findings cannot be ruled out. There is insufficient evidence to quantify the frequency, length, bout duration, intensity, and volume of the walking required to improve CVD risk factors.

word count: 250 


\section{INTRODUCTION}

Non-communicable diseases (NCD) are a major burden worldwide ${ }^{1}$. It has been estimated that elimination of physical inactivity would remove between $6 \%$ and $10 \%$ of the major NCDs of coronary heart disease (CHD), type 2 diabetes, and breast and colon cancers, and increase life expectancy ${ }^{2}$. One key approach to increase population levels of physical activity is to promote safe, accessible, and environmentally friendly activity options for all citizens, including improved infrastructure for walking and cycling for transport and recreation ${ }^{3}$.

Walking is the ideal physical activity intervention to improve health across the population ${ }^{4}$. A recent systematic review of 32 randomized controlled trials by Murtagh et al. (reference) showed that walking increases aerobic capacity and reduces blood pressure, waist circumference, body weight, percent body fat and body mass index. Another systematic review (Hanson and Jones 2015) reported similar health benefits of recreational walking including reduced systolic and diastolic blood pressure, resting heart rate, body fat, body mass index and total cholesterol, and increased $\mathrm{VO}_{2} \max$, physical functioning and the distance covered in a 6-min walk-test.

National physical activity recommendations are based on summative volumes of different intensities of physical activity over a week, with walking as the cornerstone of health promotion efforts. However, walking can vary considerably in terms of the frequency, intensity, daily/weekly duration, and total volume. Specific evidence on the dose-response relationships could increase health professionals' effectiveness in promoting physical activity, and specifically walking for health benefits.

Observational data indicate some dose response relationships at a population level. In a systematic review of epidemiological studies with all-cause mortality as the endpoint Hamer et al. (2008) found that walking pace was a stronger independent predictor than walking volume. Through meta-analysis Kelly at al. ${ }^{5}$ showed an increased reduction in the risk of all-cause mortality for higher walking volumes (in MET-hours per week). Also randomized controlled walking trials have found some dose-response relationships. Asikainen et al. (2002a) searched for the minimum dose of walking for health benefits and found that a weekly dose of 1000 to $1500 \mathrm{kcal}$ of walking improved the aerobic power and body composition of previously sedentary non-obese postmenopausal women. Recently anson and Jones ${ }^{6}$ noted based on their systematic review of randomized controlled walking trials that there is insufficient evidence to suggest any conclusions about the dose-response between the volume and intensity of walking and the health outcomes.

CVD risk factor reduction via walking promotion must be based not only on evidence of effectiveness but also on being able to identify the effects of variations in different characteristics of walking, potentially offering more options for walking. Based on the updated data of Murtagh et al (reference) our systematic review aimed to (1) update the evidence for the effects of walking interventions on CVD risk factors and in particular to (2) study the dose-response relationships

Commented [PO1]: New reference: Hamer M, Chida Y. Walkin and primary prevention: a meta-analysis of prospective cohort studies. Br J Sports Med 2008;42:238-243. 
between the frequency, intensity, duration and volume of walking interventions and CVD risk factors in healthy inactive adults.

\section{METHODS}

\section{Registration}

This study is registered in PROSPERO as CRD42016039409.

\section{Data search}

Studies (1971-2012) included in an earlier systematic review ${ }^{7}$, were supplemented by electronic searches (January 2012 - April 2017) of 4 databases: Cochrane Central Register for Controlled Trials, Medline, Web of Science and SPORTDiscus. The following search terms were used in both searches (1) walking, (2) exercise, (3) health, (4) cardiovascular risk. The full search strategy for the 2012-2017 search is enclosed as "Supplementary file". Reference lists from review and original articles were hand-searched for additional studies.

\section{Eligibility criteria}

Studies were selected based on the following inclusion/exclusion criteria: randomized controlled trials (RCTs) studying the effects of walking on one or more CVD risk factors; trials with at least one group completing walking as the only intervention; intervention duration at least 8 weeks; control group with no walking intervention; participants aged 18 years or older who were insufficiently active but otherwise healthy and capable of unaided walking (otherwise no other age limit); CVD risk factors assessed pre- and post-training (or change from pre- to post-intervention reported); English language articles published in peer-reviewed journals between January 1971 and April 2017.

\section{Study selection}

Twenty-eight studies (Aldred 1995, Anderson 2006, Asikainen 2002a, Asikainen 2002b, Baker 2008, Bell 2010, Braith 1994, Brandon 2006, Butcher 2008, Duncan 1991, Hinkleman 1993, Jette 1998, Moreau 2001, Morgan 2010, Murphy 1998, Murphy 2006, Murtagh 2005, Probart 1991, Ready 1995, Ready 1996, Santiago 1995, Serwe 2011, Stensel 1993, Stensel 1994, Tully 2005, Tully 2007, Woolf-May 1999, Woolf-May 2011) from previous review (Murtagh et al. 2015) of 32 studies were included in the current analyses. Two studies were excluded because of very old age of the participants ${ }^{89}$ and two studies because of insufficient outcome data ${ }^{1011}$. Screening of the previous review is described elsewhere ${ }^{7}$. The updated search resulted in 10 new studies for inclusion (Foulds 2014, Gaba 2016, Hamdorf 1992, Herzig 2014, Hong 2014, Jasinski 2015, Kang 2014, Kearney 2014, Pospieszna 2017, Zhang 2014). Titles and abstracts from the updated search were screened by three authors (PO, ST, PK). Full papers were screened independently for 
eligibility by two authors (PO, ST and PO, PK). Disagreements were resolved by jointly reassessing the studies against the eligibility criteria.

\section{Data extraction}

Two authors (PO, PK) extracted participant characteristics and outcome measures data independently and a third author (ST) checked the extracted data of all included studies. Disagreements were resolved by consensus. Dose attributes were defined as frequency, intensity, duration and total volume of walking, and the health outcomes for CVD risk factors as measures of cardio-metabolic fitness, adiposity and blood lipid profile. Intervention dose metrics were extracted by one author (PO) and cross-checked by a second author (ST). Missing information was sought from the authors of twelve studies ${ }^{10-21}$.

Intervention dose metrics were: frequency (sessions per week), duration of the intervention (weeks), bout duration (minutes per session), intensity as METs and \%VO2max, and volume as MET-minutes per week, and total MET-hours, (conversion formulas are indicated in the respective tables $\left.{ }^{22-24}\right)$. The outcome measures were: aerobic fitness expressed as $\mathrm{VO}_{2} \mathrm{max}\left(\mathrm{ml}^{*} \mathrm{~kg}^{-1 *} \mathrm{~min}^{-1}\right)$, body mass (kg), body fat (\%), body mass index (weight in kilograms divided by height in meters ${ }^{2}$ ), waist circumference $(\mathrm{cm})$, waist-to-hip-ratio, systolic and diastolic blood pressure $(\mathrm{mmHg})$, total cholesterol $\left(\mathrm{mmol}^{*} \mathrm{~L}^{-1}\right), \mathrm{HDL}$ cholesterol $\left(\mathrm{mmol}^{*} \mathrm{~L}^{-1}\right)$, LDL cholesterol $\left(\mathrm{mmol}^{*} \mathrm{~L}^{-1}\right)$, triglycerides $\left(\mathrm{mmol}^{*} \mathrm{~L}^{-1}\right)$, and fasting glucose $\left(\mathrm{mmol}^{*} \mathrm{~L}^{-1}\right)$. Outcomes for insulin resistance and inflammationrelated serum cytokines ${ }^{25}$, blood flow in lower extremities ${ }^{26}$, arterial stiffness ${ }^{21}$, postural stability ${ }^{27}$, bone mineral density ${ }^{27}$, and biomarkers of endothelial function ${ }^{28}$ were not included in the meta-analyses because of insufficient number of comparisons $(<10)$ (see ref ${ }^{29}$ ).

\section{Assessment of the risk of bias}

Risk of bias of individual studies was assessed by the Cochrane Collaboration tool ${ }^{29}$. Two authors (PO, EM) assessed studies independently for sequence generation, allocation concealment, blinding, incomplete outcome data, selective outcome reporting, and other potential threats to validity. Divergent ratings were re-assessed independently by a third author (MM) to reach consensus.

\section{Synthesis of results}

The software "Comprehensive Meta-Analysis" was used for all statistical analyses ${ }^{30}$. For each CVD risk factor outcome, standardized mean difference (SMD) (defined as the raw difference between the mean change in the intervention group and the mean change in the control group divided by pooled post standard deviation (SD)) was used as the summary measure. When these data were not reported, we used the reported findings as follows. For the studies by Butcher et al. ${ }^{19}$, 
Murphy et al. ${ }^{18}$, and Tully et al. ${ }^{15} 16$ we used mean change and its SD and the number of participants in each group to calculate SMD. For the study of Hamdorf et al. ${ }^{31}$ we used pre and post means and the number of participants in each group and $F$ for the difference between changes. For body mass in the study by Hinkleman et al. ${ }^{32}$ the number of participants in each group and $\mathrm{F}$ for difference between the changes were used in the formula.

Eleven studies included more than one walking intervention group. The results for each group compared to the control were treated as independent studies. The number of participants in the control group was divided by the number of intervention groups ${ }^{29}$. The effect direction was set negative for studies where a decrease represented an improvement in the health risk factor compared to the control group, and the effect direction was set positive for HDL cholesterol and $\mathrm{VO}_{2} \mathrm{max}$ as an increase represents an improvement in health risk. The following $\mathrm{Q}$ statistics were used to identify and quantify the heterogeneity in effect sizes for each CVD outcome: (1) the estimated standard deviation of the true effect size (Tau); (2) the ratio of true heterogeneity to total variation in observed effects $\left(\mathrm{I}^{2}\right)$, which can range from $0 \%$ to $100 \%$; and $(3)$ the $p$-value to test the null-hypothesis that all studies share a common effect size ${ }^{30}$. Publication bias was assessed by visual inspection of funnel plots. If a publication bias was assumed cumulative forest plots ${ }^{30}$ were used for confirmation.

Effect sizes were expressed in the original units of the outcome variables by multiplying SMD by a population representative standard deviation for the outcome ${ }^{29}$. Representative standard deviations were obtained from the MONICA Population Survey data ${ }^{33}$ for body mass, BMI, waist circumference, systolic and diastolic blood pressure and total and $\mathrm{HDL}$ cholesterol. For $\mathrm{VO}_{2} \mathrm{max}$ the SD was taken from a Norwegian study of 3816 participants ${ }^{34}$, and for percent body fat from the FINNRISK 2007 study ${ }^{35}$.

All analyses were adjusted for age. Sex was not considered a confounder because only two studies were male only. Further adjustment for sex indicated that there was no difference in the effect sizes between subgroups with females only, males only, mixed and no information.

\section{Dose-response by walking characteristics}

We conducted random-effects univariate meta-regression analysis with adjustment for age using continuous walking intervention characteristics as the covariates to test linear as well as curvilinear relationships. The dependent variable was the SMD for each CVD-outcome. In the regression models the study's weight was the inverse of the total variance for each CVD-outcome.

Meta regression results are reported as the linear $ß$-coefficient with $95 \% \mathrm{Cl}$ and $\mathrm{p}$-values. The curvilinear regressions between the MET-related doses and the outcomes were analysed by creating two variables (dose minus mean and dose minus mean squared) and testing if the interaction was significant. The Bonferroni correction (Field 2012) was applied to interpret the multiple comparison p-values. 


\section{RESULTS}

\section{Selection of studies}

We searched four electronic databases from 2012 - April 2017 to update the data of the previous systematic review (Murtagh et al 2015). The search resulted in a total of 7862 records. The screening of the titles and abstracts yielded 37 papers for potential inclusion. These were supplemented by 28 papers from the previous review ${ }^{7}$ and one paper was identified by hand searching. The full-text versions of 70 papers were then screened. Thirty-two papers were excluded due to the following reasons: mixed training content (7), non- or group-randomized design (8), non-healthy participants (8), no no-walking control group (3), incomplete outcome data (4), and unclear intervention (2). Thirty-eight eligible studies were included in the analyses. This included 28 studies from the previous review and 10 new studies. Where studies reported results using the same participants in more than one article these were combined to represent one study in the meta-analysis. Study selection is depicted in Figure 1. 


\section{Study characteristics}

Participant characteristics, study characteristics and walking intervention characteristics (session duration, frequency, and intensity as well as length of the intervention) for all 37 included studies are shown in supplementary table 1 . In brief, 22 studies $182025-28313236-4043444852-5658$ included only women, three studies ${ }^{13} 1417$ only men, and 14 studies $1215161921414245-4749-5157$ both sexes as participants. The mean age of participants ranged from 30 to 72 years. The studies included 55 walking intervention groups. Thirty studies prescribed ordinary walking, four studies treadmill walking, two studies utilized Nordic walking, and one "trekking" intervention.

\section{Exposure metrics}

Intervention dose characteristics varied considerably (Supplementary table 1 and 2): total duration 8 to 52 weeks, session duration 10 to 90 minutes, number of sessions per week 1 to 15.4 , weekly duration 10 to 325 minutes, intensity 1.7 to $5.8 \mathrm{METs}$, total weekly volume 27 to $1300 \mathrm{MET}$ minutes per week, total walking duration 130 to 10192 minutes, and total intervention volume 5.85 to 576 MET-hours.

Twenty studies reported walking intensity as either percentage of maximum heart rate (range: 50$86 \% \mathrm{HR}_{\max }$ ) $1314171836374450-525557$, percentage of $\mathrm{VO}_{2 \max }$ (range 45-65\%) 253238394754 or percentage heart rate reserve (range $54-85 \%$ ) ${ }^{425356}$. Four studies reported that walking was "selfpaced" 19414849 and seven studies noted that walking intensity was at a "brisk pace" 121516212743 ${ }^{45}$. Additionally two studies measured the intensity as walking speed ${ }^{4658}$, and one study as HR ${ }^{31}$, $\mathrm{MET}^{26}$, RPE ${ }^{20}$, and ventilator threshold ${ }^{28}$, each.

In ten studies $1920253148-50525556$ the intensity in METs could not be derived from the information provided, therefore intensity data are missing for these studies.

\section{Outcome data}

Our pooled data included sufficient number $(\geq 10)$ of comparisons in the meta-analyses for body mass (40), BMI (28), body fat (28), waist circumference (18), waist-to-hip ratio (13), systolic blood pressure (34), diastolic blood pressure (32), total cholesterol (37), HDL cholesterol (35), LDL cholesterol (34), triglycerides (34), fasting glucose (16), and $\mathrm{VO}_{2} \max (31)$. Overall, both the metaanalyses and the meta-regression analyses included 13 or more comparisons. 


\section{Risk of bias}

Results of the assessment of the risk of bias according to the Cochrane Collaboration assessment tool are shown in the Supplementary table 3. Among the 37 studies only two studies were assessed as being at low risk of bias across all domains ${ }^{12} 15$.

\section{Meta-analysis}

Pooled meta-analysis results (SMD, 95\% confidence intervals, p-value) are shown in Table 1.

Significant favorable effects $(\mathrm{p}<0.05)$ were seen for body mass, BMI, body fat, systolic and diastolic blood pressure, fasting glucose, and $\mathrm{VO}_{2}$ max. Estimated effect sizes were: body mass $-1.6 \mathrm{~kg}, \mathrm{BMI}$ $0.60 \mathrm{~kg}^{*}\left(\mathrm{~m}^{2}\right)^{-1}$, systolic blood pressure $-4.05 \mathrm{mmHg}$, diastolic blood pressure $-1.76 \mathrm{mmHg}$, and $\mathrm{VO}_{2} \max 4.86 \mathrm{ml}^{*} \mathrm{~kg}^{-1 *} \mathrm{~min}^{-1}$.

Heterogeneity, as indicated by $\mathrm{I}^{2}$, was $0 \%$ for all outcomes except for systolic (17\%) and diastolic (6\%) blood pressure, total cholesterol (16\%), and fasting glucose (23\%). 
Table 1. Meta-analysis on the effects of walking interventions on biomedical indices of health

\begin{tabular}{|l|c|c|c|c|c|c|c|}
\hline \multirow{2}{*}{ Outcome } & \multirow{2}{*}{$\mathrm{n}$} & \multicolumn{3}{|c|}{ Effect size } & \multicolumn{3}{|c|}{ Heterogeneity } \\
\cline { 5 - 8 } & & SDM & $95 \% \mathrm{Cl}$ & $\mathrm{p}$ & $\mathrm{T}$ & $\mathrm{I}^{2}(\%)$ & $\mathrm{p}$ \\
\hline Body mass & 42 & -0.134 & -0.233 to -0.034 & 0.009 & 0.000 & 0.000 & 1.000 \\
\hline BMI & 29 & -0.142 & -0.257 to -0.027 & 0.015 & 0.000 & 0.000 & 0.999 \\
\hline Body fat & 29 & -0.216 & -0.336 to -0.096 & $<0.001$ & 0.000 & 0.000 & 0.999 \\
\hline WC & 18 & -0.104 & -0.265 to 0.058 & 0.208 & 0.000 & 0.000 & 0.998 \\
\hline WHR & 13 & -0.165 & -0.340 to 0.009 & 0.063 & 0.000 & 0.000 & 0.668 \\
\hline SBP & 35 & -0.213 & -0.344 to -0.082 & 0.001 & 0.164 & 17.981 & 0.178 \\
\hline DBP & 33 & -0.166 & -0.285 to -0.047 & 0.006 & 0.067 & 3.650 & 0.408 \\
\hline TC & 38 & -0.123 & -0.242 to 0.001 & 0.052 & 0.150 & 15.547 & 0.205 \\
\hline HDL-C & 36 & 0.035 & -0.080 to 0.150 & 0.553 & 0.000 & 0.000 & 1.000 \\
\hline LDL-C & 35 & 0.030 & -0.089 to 0.148 & 0.624 & 0.000 & 0.000 & 0.630 \\
\hline TG & 35 & -0.084 & -0.201 to 0.033 & 0.161 & 0.000 & 0.000 & 0.876 \\
\hline FG & 17 & -0.211 & -0.401 to -0.022 & 0.029 & 0.186 & 23.343 & 0.183 \\
\hline VO ${ }_{2}$ max & 31 & 0.528 & 0.391 to 0.664 & $<0.001$ & 0.000 & 0.000 & 0.715 \\
\hline All & & & & & & & \\
\hline
\end{tabular}

All estimates are from the meta-analysis using the random-effects model comparing an intervention group (walking) with a control group (no intervention)

$\mathrm{n}=$ number of comparisons

body mass $(\mathrm{kg}), \mathrm{BMI}=$ body mass index $\left(\mathrm{kg} / \mathrm{m}^{2}\right), \mathrm{SBP}=$ systolic blood pressure $\left(\mathrm{mmol}^{*} \mathrm{~L}^{-1}\right), \mathrm{DBP}=$ diastolic blood pressure $\left(\mathrm{mmol}^{*} \mathrm{~L}^{-1}\right), \mathrm{TC}=$ total cholesterol $\left(\mathrm{mmol}^{*} \mathrm{~L}^{-1}\right), \mathrm{HDL}-\mathrm{C}=$ high-density lipoprotein cholesterol $\left(\mathrm{mmol}^{*} \mathrm{~L}^{-1}\right), \mathrm{LDL}-\mathrm{C}=$ low-density lipoprotein cholesterol $\left(\mathrm{mmol}^{*} \mathrm{~L}^{-1}\right), \mathrm{TG}=$ triglycerides $\left(\mathrm{mmol}^{*} \mathrm{~L}^{-1}\right), \mathrm{FG}=$ fasting glucose $\left(\mathrm{mmol}^{*} \mathrm{~L}^{-1}\right), \mathrm{VO}_{2} \mathrm{max}=$ maximal oxygen uptake

SDM = standardized difference in means, $\mathrm{Cl}=$ confidence interval, $\mathrm{p}$-value for SDM (test of the null hypothesis that the effect is zero), $\mathrm{T}=\mathrm{Tau}$ (estimate of the standard deviation in true effect sizes), $\mathrm{I}^{2}=$ heterogeneity (ratio of true heterogeneity to total observed variation), $p$-value (test of the null hypothesis that all studies in the analysis share a common effect size)

Funnel plots for the outcomes showed symmetric patterns suggesting non-significant publication bias except those for body fat and LDL (see supplementary file 1)). Cumulative forest plots of these outcomes (see supplementary file 1) showed symmetric pattern of the effect sizes even with the 
less precise studies included, thus suggesting that there is no reason to assume a publication bias 30.

\section{Meta regression and dose-response by walking dose characteristics}

The linear meta-regression analyses for (i) walking frequency (number of session per week), (ii) intervention duration (weeks) and (iii) session duration (minutes) showed three significant $(p \leq 0.05)$ positive associations from 39 possible dose-response relationships [intervention duration with LDL-cholesterol $(p=0.001)$ and $\mathrm{VO}_{2} \max (p=0.018)$, and session duration with triglycerides $(p=0.029)$ ], and one inverse association [session duration with systolic blood pressure $(p=0.050)$ ] (table 2). 
Table 2. Meta regression analysis: frequency, intervention duration, session duration (adjusted model\#)

\begin{tabular}{|c|c|c|c|c|c|c|c|c|c|c|c|c|}
\hline \multirow[t]{2}{*}{ Outcome } & \multicolumn{4}{|c|}{$\begin{array}{l}\text { Frequency, } \\
\text { sessions per week }\end{array}$} & \multicolumn{4}{|c|}{$\begin{array}{l}\text { Duration of intervention, } \\
\text { weeks }\end{array}$} & \multicolumn{4}{|c|}{$\begin{array}{l}\text { Duration of session, } \\
\text { minutes }\end{array}$} \\
\hline & $\mathrm{n}$ & $\beta$ & $95 \% \mathrm{Cl}$ & $p$ & $n$ & $\beta$ & $95 \% \mathrm{Cl}$ & $p$ & $\mathrm{n}$ & $\beta$ & $95 \% \mathrm{Cl}$ & $p$ \\
\hline Body mass & 42 & -0.0020 & -0.0390 to 0.0429 & 0.924 & 42 & 0.0007 & -0.0097 to 0.0110 & 0.898 & 39 & -0.0016 & -0.0077 to 0.0045 & 0.608 \\
\hline $\mathrm{BMI}$ & 29 & -0.0068 & -0.0552 to 0.0417 & 0.785 & 29 & 0.0008 & -0.0111 to 0.0126 & 0.900 & 28 & 0.0018 & -0.0051 to 0.0086 & 0.614 \\
\hline Body fat & 29 & 0.0136 & -0.0542 to 0.0815 & 0.694 & 29 & -0.0005 & -0.0119 to 0.0110 & 0.938 & 26 & -0.0024 & -0.0094 to 0.0046 & 0.506 \\
\hline WC & 18 & 0.0041 & -0.0523 to 0.0604 & 0.887 & 18 & -0.0016 & -0.0276 to 0.0244 & 0.903 & 18 & -0.0009 & -0.0127 to 0.0110 & 0.886 \\
\hline WHR & 14 & 0.0046 & -0.1122 to 0.1215 & 0.938 & 14 & 0.0020 & -0.0126 to 0.0164 & 0.785 & 14 & 0.0009 & -0.0128 to 0.0145 & 0.899 \\
\hline SBP & 35 & 0.0418 & -0.0058 to 0.0885 & 0.085 & 35 & 0.0073 & -0.0153 to 0.0288 & 0.527 & 34 & -0.0075 & -0.0150 to -0.000 & 0.050 \\
\hline$\overline{D P B}$ & 33 & -0.0247 & -0.0743 to 0.0249 & 0.328 & 33 & 0.0135 & 0.0061 to 0.0330 & 0.177 & 32 & -0.0029 & -0.0096 to 0.0039 & 0.408 \\
\hline TC & 38 & 0.0393 & -0.0163 to 0.0950 & 0.166 & 38 & 0.0108 & -0.0108 to 0.0233 & 0.093 & 35 & -0.0038 & -0.0114 to 0.0039 & 0.338 \\
\hline HDL-C & 36 & 0.0035 & -0.0492 to 0.0562 & 0.895 & 36 & 0.0012 & -0.0103 to 0.0127 & 0.838 & 33 & -0.0004 & -0.0102 to 0.0093 & 0.931 \\
\hline LDL-C & 35 & 0.0367 & -0.0172 to 0.0905 & 0.182 & 35 & 0.0202 & 0.0081 to 0.0323 & 0.001 & 33 & -0.0055 & -0.0151 to 0.0040 & 0.256 \\
\hline TG & 33 & -0.0004 & -0.0534 to 0.0526 & 0.989 & 33 & 0.0000 & -0.0183 to 0.0183 & 0.999 & 31 & 0.0077 & 0.0008 to 0.0146 & 0.029 \\
\hline$\overline{F G}$ & 17 & -0.0420 & -0.1372 to 0.0533 & 0.388 & 17 & -0.0085 & -0.0476 to 0.0306 & 0.671 & 16 & -0.0062 & -0.0170 to 0.0046 & 0.261 \\
\hline $\mathrm{VO}_{2} \max$ & 31 & -0.0125 & -0.0639 to 0.0389 & 0.633 & 31 & 0.0254 & 0.0043 to 0.0465 & 0.018 & 29 & 0.0071 & -0.0024 to 0.0165 & 0.142 \\
\hline
\end{tabular}

\section{\# adjusted for age}

$\mathrm{n}=$ number of comparisons

$\beta=$ linear regression coefficient, $\mathrm{Cl}=$ confidence interval,

Body mass $(\mathrm{kg}), \mathrm{BMI}=$ body mass index $\left[\mathrm{kg}^{*}\left(\mathrm{~m}^{2}\right)^{-1}\right]$, body fat $(\%), \mathrm{WC}=$ waist circumferences $(\mathrm{cm}), \mathrm{WHR}=$ waist to hip ratio, $\mathrm{SBP}=$ systolic blood pressure $(\mathrm{mm} \mathrm{Hg}), \mathrm{DBP}=$ diastolic blood pressure $(\mathrm{mm} \mathrm{Hg}), \mathrm{TC}=$ total cholesterol $\left(\mathrm{mmol}^{*} \mathrm{~L}^{-1}\right), \mathrm{HDL}-\mathrm{C}=$ high-density lipoprotein cholesterol $\left(\mathrm{mmol}^{*} \mathrm{~L}^{-1}\right), \mathrm{LDL}-\mathrm{C}=\mathrm{low}-$ density lipoprotein cholesterol $\left(\mathrm{mmol}^{*} \mathrm{~L}^{-1}\right), \mathrm{TG}=$ triglycerides $\left.\left(\mathrm{mmol}^{*} \mathrm{~L}^{-1}\right)\right), \mathrm{FG}=$ fasting glucose $\left(\mathrm{mmol}^{*} \mathrm{~L}^{-1}\right), \mathrm{VO}_{2} \max =\operatorname{maximal}$ oxygen uptake $\left(\mathrm{ml}^{*} \mathrm{~kg}^{-1 *} \mathrm{~min}^{-1}\right)$ 
The linear meta-regression analysis between the three MET related metrics (METs, MET-minutes per week, total MET-hours) and the outcomes resulted in three positive associations from a possible 39: METs with $\mathrm{VO}_{2} \max (p=0.049)$, MET-min per week with triglycerides $(p=0.009)$, and total MET-hours with LDL-cholesterol $(p=0.007)$ ] (Table 3$)$. We found one positive relationships to be significantly curvilinear after adjustment for multiple testing: intensity in METs with LDLcholesterol (results not shown).

Respective linear analysis with the relative intensity dose $\left(\% \mathrm{VO}_{2} \mathrm{max}\right)$ yielded one inverse association: $\% \mathrm{VO}_{2} \max$ with diastolic blood pressure $(\mathrm{p}=0.020)$ ] (Table 4). 
Table 3. Meta regression analysis: MET-related doses (adjusted model ${ }^{\#)}$

\begin{tabular}{|c|c|c|c|c|c|c|c|c|c|c|}
\hline \multirow[t]{2}{*}{ Outcome } & \multirow[b]{2}{*}{$\mathrm{n}$} & \multicolumn{3}{|l|}{ METs } & \multicolumn{3}{|c|}{ MET-minutes per week } & \multicolumn{3}{|c|}{ MET-hours total } \\
\hline & & $\beta$ & $95 \% \mathrm{Cl}$ & $\mathrm{p}$ & $\beta$ & $95 \% \mathrm{Cl}$ & $\mathrm{p}$ & $\beta$ & $95 \% \mathrm{Cl}$ & $p$ \\
\hline Body mass & 34 & -0.0613 & -0.1979 to 0.0752 & 0.378 & -0.0002 & -0.0005 to 0.0002 & 0.337 & -0.0002 & -0.0008 to 0.0005 & 0.640 \\
\hline BMI & 24 & -0.0265 & -0.2147 to 0.1617 & 0.782 & -0.0000 & -0.0004 to 0.0004 & 0.937 & -0.0000 & -0.0007 to 0.0007 & 0.961 \\
\hline Body fat & 23 & -0.1309 & -0.2927 to 0.0309 & 0.113 & -0.0003 & -0.0007 to 0.0001 & 0.163 & -0.0002 & -0.0009 to 0.0005 & 0.518 \\
\hline WC & 14 & -0.1696 & -0.4420 to 0.1023 & 0.222 & -0.0003 & -0.0011 to 0.0005 & 0.499 & -0.0004 & -0.0013 to 0.0011 & 0.572 \\
\hline WHR & 13 & -0.0231 & -0.3677 to 0.3215 & 0.896 & 0.0001 & -0.0008 to 0.0011 & 0.763 & 0.0002 & -0.0007 to 0.0011 & 0.678 \\
\hline SBP & 28 & -0.0254 & -0.2027 to 0.1519 & 0.779 & 0.0003 & -0.0001 to 0.0007 & 0.154 & 0.0006 & -0.0005 to 0.0016 & 0.270 \\
\hline DPB & 26 & -0.1528 & -0.3185 to 0.0129 & 0.071 & -0.0001 & -0.0006 to 0.0003 & 0.544 & -0.0000 & -0.0010 to 0.0010 & 0.988 \\
\hline TC & 33 & 0.1390 & -0.0432 to 0.3213 & 0.135 & 0.0003 & -0.0001 to 0.0007 & 0.148 & 0.0006 & -0.0002 to 0.0013 & 0.133 \\
\hline $\mathrm{HDL}-\mathrm{C}$ & 32 & 0.0391 & -0.1233 to 0.2014 & 0.637 & 0.0001 & -0.0003 to 0.0004 & 0.772 & 0.0001 & -0.0006 to 0.0008 & 0.737 \\
\hline LDL-C & 32 & 0.1124 & -0.0503 to 0.2751 & 0.176 & 0.0002 & -0.0002 to 0.0006 & 0.292 & 0.0010 & 0.0003 to 0.0017 & 0.007 \\
\hline TG & 23 & 0.1251 & -0.0384 to 0.2886 & 0.134 & 0.0005 & 0.0001 to 0.0009 & 0.009 & 0.0008 & -0.0001 to 0.0018 & 0.086 \\
\hline $\mathrm{FG}$ & 14 & -0.1564 & -0.4049 to 0.0921 & 0.217 & -0.0005 & -0.0011 to 0.0000 & 0.064 & -0.0010 & -0.0025 to 0.0005 & 0.185 \\
\hline $\mathrm{VO}_{2} \max$ & 29 & 0.1612 & 0.0006 to 0.3218 & 0.049 & 0.0003 & -0.0001 to 0.0008 & 0.115 & 0.0009 & -0.0002 to 0.0020 & 0.106 \\
\hline
\end{tabular}

\# adjusted for age

$\mathrm{n}=$ number of comparisons

$\beta=$ linear regression coefficient, $\mathrm{Cl}=$ confidence interval

Body mass $(\mathrm{kg}), \mathrm{BMI}=$ body mass index $\left(\mathrm{kg} / \mathrm{m}^{2}\right)$, body fat $(\%), \mathrm{WC}=$ waist circumferences $(\mathrm{cm}), \mathrm{WHR}=$ waist to hip ratio, $\mathrm{SBP}=$ systolic blood pressure $(\mathrm{mm} \mathrm{Hg})$, $\mathrm{DBP}=$ diastolic blood pressure $(\mathrm{mm} \mathrm{Hg}), \mathrm{TC}=$ total cholesterol $\left(\mathrm{mmol}^{*} \mathrm{~L}^{-1}\right), \mathrm{HDL}=$ high-density lipoprotein cholesterol $\left(\mathrm{mmol}^{*} \mathrm{~L}^{-1}\right), \mathrm{LDL}=$ low-density lipoprotein cholesterol $\left(\mathrm{mmol}^{*} \mathrm{~L}^{-1}\right), \mathrm{TG}=$ triglycerides $\left(\mathrm{mmol}^{*} \mathrm{~L}^{-1}\right), \mathrm{FG}=$ fasting glucose $\left(\mathrm{mmol}^{*} \mathrm{~L}^{-1}\right), \mathrm{VO}_{2} \mathrm{max}=$ maximal oxygen uptake $\left(\mathrm{ml}^{*} \mathrm{~kg}^{-1 *} \mathrm{~min}^{-1}\right)$ 
Table 4. Meta regression analysis: $\% \mathrm{VO}_{2}$ max dose (adjusted model $\left.{ }^{\#}\right)$

\begin{tabular}{|c|c|c|c|c|}
\hline \multirow[t]{2}{*}{ Outcome } & \multirow[b]{2}{*}{$\mathrm{n}$} & \multicolumn{3}{|c|}{$\% \mathrm{VO}_{2} \max$ dose } \\
\hline & & B & $95 \% \mathrm{Cl}$ & $\mathrm{p}$ \\
\hline Body mass & 23 & -0.0051 & -0.0228 to 0.0126 & 0.574 \\
\hline BMI & 14 & -0.0073 & -0.0362 to 0.0216 & 0.620 \\
\hline Body fat & 14 & -0.0080 & 0.0318 to 0.0157 & 0.506 \\
\hline WC & 8 & 0.0180 & -0.0338 to 0.0698 & 0.496 \\
\hline WHR & 5 & 0.0316 & -0.0357 to 0.0989 & 0.357 \\
\hline SBP & 19 & -0.0197 & -0.0409 to 0.0015 & 0.068 \\
\hline DBP & 17 & -0.0235 & -0.0433 to -0.0037 & 0.020 \\
\hline TC & 19 & 0.0032 & -0.0193 to 0.0257 & 0.781 \\
\hline HDL-C & 18 & -0.0027 & -0.0252 to 0.0197 & 0.812 \\
\hline LDL-C & 19 & $0-0017$ & -0.0223 to 0.0256 & 0.892 \\
\hline TG & 18 & 0.0068 & -0.0158 to 0.0294 & 0.555 \\
\hline FG & 8 & -0.0252 & -0.0570 to 0.0066 & 0.120 \\
\hline $\mathrm{VO}_{2} \max$ & 24 & 0.0161 & -0.0019 to 0.0342 & 0.080 \\
\hline
\end{tabular}

\# adjusted for age

$\mathrm{n}=$ number of comparisons

$B=$ linear regression coefficient, $\mathrm{Cl}=$ confidence interval,

Body mass $(\mathrm{kg}), \mathrm{BMI}=$ body mass index, body fat $(\%), \mathrm{WC}=$ waist circumferences $(\mathrm{cm}), \mathrm{WHR}=$ waist to hip ratio, $\mathrm{SBP}=$ systolic blood pressure $(\mathrm{mmHg}), \mathrm{DBP}=$ diastolic blood pressure $(\mathrm{mmHg}), \mathrm{TC}=$ total cholesterol $\left(\mathrm{mmol}^{*} \mathrm{~L}^{-1}\right), \mathrm{HDL}=$ high-density lipoprotein cholesterol $\left(\mathrm{mmol}^{*} \mathrm{~L}^{-1}\right), \mathrm{LDL}=$ low-density lipoprotein cholesterol $\left(\mathrm{mmol}^{*} \mathrm{~L}^{-1}\right), \mathrm{TG}=$ Triglycerides $\left(\mathrm{mmol}^{*} \mathrm{~L}^{-1}\right), \mathrm{FG}=$ fasting glucose $\left(\mathrm{mmol}^{*} \mathrm{~L}^{-1}\right)$, $\mathrm{VO}_{2} \max =$ maximal oxygen uptake $\left(\mathrm{ml}^{*} \mathrm{~kg}^{-1} \mathrm{~min}^{-1}\right)$ 


\section{DISCUSSION}

Despite multiple studies and tested metrics only a few significant dose-response relationships between the walking doses and the CVD outcomes were identified and the possibility of chance findings cannot be ruled out. This review suggests that there is insufficient evidence to quantify the frequency, length, bout duration, intensity, and volume of the walking required to improve CVD risk profile.

Our meta-analysis showed significant positive impact of walking on seven CVD risk factors; body mass, $\mathrm{BMI}$, body fat, systolic and diastolic blood pressure, fasting glucose, and $\mathrm{VO}_{2}$ max. These findings are consistent with those of Murtagh et al. ${ }^{7}$ except that of waist circumference, for which they found a statistically significant effect but we did not, and the new finding of decreased fasting glucose in the present review.

Murtagh et al. (2015) evaluated the clinical significance of their findings and concluded that the found increase in VO2max would account for $15 \%$ reduction in mortality, the decreased systolic and diastolic blood pressure for ten and seven \% reduction in mortality, respectively, and the decreased in BMI for ?? reduction in ???. As the found impacts in the current analyses were of greater magnitude than reported by Murtagh et $\mathrm{al}^{7}(2015)$, and there was the additional decrease of fasting glucose, the found changes in the CVD risk factors can be considered clinically substantial.

There was no indication of publication bias in the cumulative Funnel Plots but the quality of studies was variable. Due to incomplete reporting the risk of bias in sequence generation, allocation concealment, and blinding could not be assessed for the majority (76 to $84 \%$ ) of studies. In contrast low risk of bias for outcome analysis and reporting, and for other potential sources of bias was assessed for the majority (65 to $95 \%$ ) of the included studies. These observations highlight the need for careful execution and full reporting of future walking trials according to the current quality criteria to ensure the validity of the findings.

Adherence to the exercise protocol may have an impact on the reported outcome results. Actual adherence is likely to be smaller than intended, especially in long lasting interventions, and the difference may lead to overestimation of the dose needed for changes. In our data of 37 studies 22 studies reported adherence rate and 15 did not. The reported adherence rates varied between $67 \%$ and $100 \%$ with 17 studies reporting over $80 \%$ adherence. While it is possible that the nonreporting studies had lower adherence the high rates in the majority of the studies suggest that the possible overestimation of the dose may not substantial. We performed post-hoc sub-group and mixed-effect analyses comparing studies with adherence rates over and below $90 \%$ for all study outcomes. The results indicated no statistically significant differences in any of the outcomes. 
Sufficient sample sizes are needed for reliable results. We examined our data from this perspective by conducting post-hoc sub-group and mixed-effects analyses comparing study group sizes over and below 20 (per study arm) for all outcome variables. The sub-group analysis indicated statistically significant differences between the two sample sizes for fasting glucose, systolic blood pressure and LDL-Cholesterol. Subsequent mixed-effects analyses showed no differences between the two groups for LDL-Cholesterol, and statistically significant differences for fasting glucose and systolic blood pressure. Overall the sample size affected only two of the 13 outcomes, which may also be due to the multiple comparisons.

In our study we have attempted to explore the dose-response between walking characteristics and CVD risk factors using meta-regression analysis. One assumption for the use of meta-regression is sufficient heterogeneity in the outcome effects, i.e. some of the variance across the included studies is real. We found some (4-23\%) heterogeneity as measured by the statistic $\mathrm{I}^{2}$ in four and no heterogeneity in nine outcomes. This low level of heterogeneity may explain the fact that we found only a few statistically significant dose-response associations.

Moreover, as the meta-regression analyses included multiple comparisons between the dose and the outcomes (each 13 comparisons) there is a risk of overestimating the statistical significance. A more conservative $p$-value for our multiple testing would be between $p<0.004$ to 0.002 according to Bonferroni ${ }^{59}$. All but one (weeks of intervention with LDL) of the found $p$-values for the regressions were greater than this. We therefore did not find any evidence that the response of the CVD risk factors is associated with the walking dose characteristics used in this study.

The dose of walking in METs represents the absolute intensity, which confers different levels of relative physiological load across individuals with different capacity. Thus a dose of 5 METs may mean $50 \%$ of the capacity of a person with good cardiorespiratory fitness and $80 \%$ of the capacity of a person with low fitness. This means that the METs intensity is only an estimate of the absolute but not the relative physiological stimulus. Physiological load relative to maximum is likely to be the key stimulus for many of the alterations in health outcomes being considered. We found one significant positive response $\left(\mathrm{VO}_{2} \max , \mathrm{p}=0.049\right)$ for the METs dose. Maximal oxygen uptake is the gold standard for aerobic fitness. The percent level of $\mathrm{VO}_{2}$ max of training represents a good measure of the relative physiological training stimulus. We had 20 studies with $\%_{\mathrm{VO}_{2}}$ max intensity (reported or converted). In all these studies the training intensity was determined by individual heart rate monitoring (19 studies) or walking speed (1 study) derived from laboratory assessment. Thus the relative intensity dose was physiologically controlled at the group level. The regression analysis (Table 4 ) resulted in a significant $(p=0.020)$ inverse association between the $\% \mathrm{VO}_{2}$ max dose and diastolic blood pressure. As this $p$-value does not reach the conservative significance $p$ level of $0.004{ }^{59}$, the response of the CVD risk factors is likely to be independent also of the relative intensity dose. 
In order to put our findings in the context of current physical activity recommendations we can use MET-minutes per week dose, which combines the frequency, bout duration and intensity, as the bases. WHO ${ }^{60}$ recommends 150 minutes of moderate-intensity aerobic physical activity per week for health benefits. Applying 3 METs as the lower limit of moderate-intensity activity, the weekly minimum recommended dose is $450 \mathrm{MET}$-minutes. Our results indicate that walking within the range of approximately 100 to 1300 MET-min per week can benefit CVD risk factors. Thus according to our results even less than the recommended amount of weekly walking (e.g. 450 MET-minutes) may be health-promoting for inactive middle-aged and older people. This is in line with a recent evidence summary, which suggests that approximately 200 MET-min per week is sufficient for health benefits ${ }^{61}$.

\section{Strengths and weaknesses}

Our systematic review including 38 studies published between 1971 and 2017 identified a large number of randomized controlled walking trials conducted according to a standard set of quantitative criteria. The data set consisted of 28 studies from a previous review (Murtagh et al. 2015) and ten new studies. This data set included 2001 participants and 55 comparisons between intervention and control groups and a commonly accepted set of the most important CVD risk factors, allowing for rigorous meta-analysis of the main effects of walking, and yielding robust effect sizes in several outcomes. Extraction of clearly defined walking dose characteristics enabled unique meta-regression analysis for the dose-response between walking attributes and health outcomes. In addition, both the linear and the curvilinear relationships were tested. To our knowledge this is the first attempt to explore the dose-response patterns with meta-regression analysis of data from randomized controlled walking trials.

The study is not without weaknesses. We were not able to perform an individual participant data analysis using the primary data for each study but relied on aggregated data across studies resulting in increasing intra and inter study heterogeneity, and potentially regression to the mean. The low level of heterogeneity of the changes in the outcomes across the studies may have limited the power to detect dose-response relationships. The used dose metrics had to be converted from a variety of respective measures leading in several cases to estimated levels of the dose. The quality of the included studies was variable. In particular the sequence generation, allocation concealment and blinding in the trials was less than adequate in many studies. This may attenuate the precision of the effect sizes, although the direction of the observed effects was consistent. Another weakness concerns the generalizability of the findings. Participants in the studies were mostly healthy but inactive women so direct applicability to men and individuals with pre-existing chronic disease may be questioned. However, based on recent evidence on the effects of PA on health and on the resulting PA recommendations there appears very few differences between women and men. Moreover, as 35 of the 38 studies came from Europe, United states, Canada and Australia the findings may not be applicable to lower and middle income countries. 


\section{SUMMARY AND CONCLUSIONS}

Meta-analysis of data from 37 randomized controlled walking trials revealed significant improvements in seven CVD risk factors: decreases in body mass, BMI, body fat, systolic and diastolic blood pressure, fasting glucose, and an increase in $\mathrm{VO}_{2}$ max. The effect sizes indicate clinically important improvements in CVD risk profile. There were non-significant effects on six CVD risk factors: waist-hip ratio and waist circumference, and in total-, HDL-, and LDL-cholesterol and triglycerides.

Our meta-regression analyses did not find associations between the observed effects on the CVD risk factors and the frequency, length, bout duration, intensity and volume of the walking training. These results suggest that any walking exposure within the dose range of the included studies is likely to be beneficial for cardiovascular health. Current practice, population health promotion and exercise referral should reflect this. As these controlled intervention studies were designed and implemented for healthy but inactive middle-aged and older women and men, the findings demonstrate the health potential of everyday walking for large segments of populations. Walking still remains firmly a "best buy" for public health.

\section{REFERENCES}

1. Andersen LB, Mota J, Di Pietro L. Update on the global pandemic of physical inactivity. The Lancet 2016;388(10051):1255.

2. Lee I-M, Shiroma EJ, Lobelo F, et al. Effect of physical inactivity on major non-communicable diseases worldwide: an analysis of burden of disease and life expectancy. The Lancet 2012;380:219-29.

3. Reis RS, Salvo D, Ogilvie D, et al. Scaling up physical activity interventions worldwide: stepping up to larger and smarter approaches to get people moving. The Lancet 2016;388(10051):1337-48.

4. Hardman AE, Morris JN. Walking to health. Br J Sports Med 1998;32(2):184-84.

5. Kelly $P$, Kahlmeier S, Götschi T, et al. Systematic review and meta-analysis of reduction in all-cause mortality from walking and cycling and shape of dose response relationship. Int J Behav Nutr Phys Activ 2014;11

6. Hanson $\mathrm{S}$, Jones $\mathrm{A}$. Is there evidence that walking groups have health benefits? A systematic review and meta-analysis. Br J Sports Med 2015;49(11):710-15.

7. Murtagh EM, Nichols L, Mohammed MA, et al. The effect of walking on risk factors for cardiovascular disease: An updated systematic review and meta-analysis of randomised control trials. Prev Med 2015;72:34-43.

8. Hamdorf PA, Penhall RK. Walking with its training effects on the fitness and activity patterns of 79-91 year old females. Aust N Z J Med 1999;29(1):22-28.

9. Simons R, Andel R. The effects of resistance training and walking on functional fitness in advanced old age. J Aging Health 2006;18(1):91-105.

10. Osei-Tutu KB, Campagna PD. The effects of short-vs. long-bout exercise on mood, VO2max., and percent body fat. Prev Med 2005;40(1):92-98.

11. Aldred S, Rohalu M. A moderate intensity exercise program did not increase the oxidative stress in older adults. Arch Gerontol Geriatr 2011;53:350-53.

12. Baker G, Gray S, Wright A, et al. The effect of a pedometer-based community walking intervention" Walking for Wellbeing in the West" on physical activity levels and health outcomes: a 12-week 
randomized controlled trial. The International Journal of Behavioral Nutrition and Physical Activity 2008;5:44.

13. Stensel DJ, Hardman AE, Brookewavell K, et al. Brisk Walking and Serum-Lipoprotein Variables in Formerly Sedentary Men Aged 42-59 Years. Clin Sci 1993;85(6):701-08.

14. Stensel DJ, Brookewavell K, Hardman AE, et al. The Influence of a 1-Year Program of Brisk Walking on Endurance Fitness and Body-Composition in Previously Sedentary Men Aged 42-59 Years. Eur J Appl Physiol 1994;68(6):531-37.

15. Tully MA, Cupples ME, Chan WS, et al. Brisk walking, fitness, and cardiovascular risk: a randomized controlled trial in primary care. Prev Med 2005;41(2):622-28.

16. Tully MA, Cupples ME, Hart ND, et al. Randomised controlled trial of home-based walking programmes at and below current recommended levels of exercise in sedentary adults. J Epidemiol Community Health 2007;61(9):778-83. doi: 10.1136/jech.2006.053058

17. Woolf-May K, Scott A, Kearney E, et al. The effect of 24 weeks of moderate intensity walking upon metabolic syndrome risk factors in previously sedentary/low active men. Journal of Exercise Physiology 2011;14(4)

18. Murphy MH, Hardman AE. Training effects of short and long bouts of brisk walking in sedentary women. Med Sci Sports Exerc 1998;30(1):152-57.

19. Butcher LR, Thomas A, Backx K, et al. Low-Intensity Exercise Exerts Beneficial Effects on Plasma Lipids via PPAR [gamma]. Med Sci Sports Exerc 2008;40(7):1263-70.

20. Kang S-J. Trekking exercise promotes cardiovascular health and fitness benefits in older obese women. Journal of exercise rehabilitation 2014;10(4):225.

21. Kearney TM, Murphy MH, Davison GW, et al. Accumulated brisk walking reduces arterial stiffness in overweight adults: evidence from a randomized control trial. Journal of the American Society of Hypertension 2014;8(2):117-26.

22. Oja P. Intensity and frequency of physical conditioning as determinants of the cardiovascular response of middle-aged men at rest and during exercise. Pennsylvania State University, 1973.

23. Ainsworth BE, Haskell WL, Whitt MC, et al. Compendium of Physical Activities: an update of activity codes and MET intensities. Med Sci Sports Exerc 2000;32(9, Suppl.):498-516.

24. American College of Sports Medicine. ACSM's Guidelines for Exercise Testing and Prescription. 9th ed. Philadelphia: Lippincott Williams \& Wilkins 2014:162-177.

25. Hong H-R, Jeong J-O, Kong J-Y, et al. Effect of walking exercise on abdominal fat, insulin resistance and serum cytokines in obese women. Journal of Exercise Nutrition \& Biochemistry 2014;18(3):277.

26. Jasiński R, Socha M, Sitko L, et al. Effect of nordic walking and water aerobics training on body composition and the blood flow in lower extremities in elderly women. Journal of human kinetics 2015;45(1):113-22.

27. Gába A, Cuberek R, Svoboda Z, et al. The effect of brisk walking on postural stability, bone mineral density, body weight and composition in women over 50 years with a sedentary occupation: a randomized controlled trial. BMC women's health 2016;16(1):63.

28. Pospieszna B, Karolkiewicz J, Tarnas J, et al. Influence of 12-week Nordic Walking training on biomarkers of endothelial function in healthy postmenopausal women. The Journal of sports medicine and physical fitness 2017;57(9):1178-85.

29. Higgins J, Green Se. Cochrane Handbook for Systematic Reviews of Interventions Version 5.1.0 [updated March 2011]. Available from www.cochrane-handbook.org2011.

30. Borenstein M, Hedges LV, Higgins JPT, et al. Introduction to Meta-Analysis. Chichester: John Wiley \& Sons, Ltd 2009.

31. Hamdorf PA, Withers RT, Penhall RK, et al. Physical-Training Effects on the Fitness and Habitual Activity Patterns of Elderly Women. Arch Phys Med Rehabil 1992;73(7):603-08.

32. Hinkleman LL, Nieman DC. The Effects of a Walking Program on Body-Composition and Serum- Lipids and Lipoproteins in Overweight Women. J Sports Med Phys Fitness 1993;33(1):49-58.

33. Tolonen H, Kuulasmaa K, Ruokokoski E-. MONICA Population Survey Data Book: WHO MONICA Project e-publications, 2000. 
34. Loe $H$, Rognmo $\varnothing$, Saltin B, et al. Aerobic capacity reference data in 3816 healthy men and women 2090 years. PLoS ONE 2013;8(5):e64319.

35. Kanerva N, Kaartinen NE, Ovaskainen M-L, et al. A diet following Finnish nutrition recommendations does not contribute to the current epidemic of obesity. Public Health Nutr 2013;16(5):786-94.

36. Aldred HE, Hardman AE, Taylor S. Influence of 12 Weeks of Training by Brisk Walking on Postprandial Lipemia and Insulinemia in Sedentary Middle-Aged Women. Metabolism-Clinical and Experimental 1995;44(3):390-97.

37. Anderson AG, Murphy MH, Murtagh E, et al. An 8-week randomized controlled trial on the effects of brisk walking, and brisk walking with abdominal electrical muscle stimulation on anthropometric, body composition, and self-perception measures in sedentary adult women. Psychology of Sport \& Exercise 2006;7(5):437-51.

38. Asikainen TM, Miilunpalo S, Oja $\mathrm{P}$, et al. Randomised, controlled walking trials in postmenopausa women: the minimum dose to improve aerobic fitness? Br J Sports Med 2002;36(3):189-94.

39. Asikainen TM, Miilunpalo S, Oja P, et al. Walking trials in postmenopausal women: effect of one vs two daily bouts on aerobic fitness. Scand J Med Sci Sports 2002;12(2):99-105.

40. Asikainen TM, Miilunpalo S, Kukkonen-Harjula K, et al. Walking trials in postmenopausal women: effect of low doses of exercise and exercise fractionization on coronary risk factors. Scand J Med Sci Sports 2003;13(5):284-92.

41. Bell GJ, Harber V, Murray T, et al. A Comparison of Fitness Training to a Pedometer-Based Walking Program Matched for Total Energy Cost. J Phys Act Health 2010;7(2):203-13.

42. Braith RW, Pollock ML, Lowenthal DT, et al. Moderate and High-Intensity Exercise Lowers BloodPressure in Normotensive Subjects 60 to 79 Years of Age. Am J Cardiol 1994;73(15):1124-28.

43. Brandon LJ, Elliott-Lloyd MB. Walking, body composition, and blood pressure dose-response in African American and white women. Ethn Dis 2006;16(3):675.

44. Duncan JJ, Gordon NF, Scott CB. Women Walking for Health and Fitness - How Much Is Enough. JamaJournal of the American Medical Association 1991;266(23):3295-99.

45. Foulds HJ, Bredin SS, Charlesworth SA, et al. Exercise volume and intensity: a dose-response relationship with health benefits. Eur J Appl Physiol 2014;114(8):1563-71.

46. Herzig K, Ahola R, Leppäluoto J, et al. Light physical activity determined by a motion sensor decreases insulin resistance, improves lipid homeostasis and reduces visceral fat in high-risk subjects: PreDiabEx study RCT. International journal of obesity (2005) 2014;38(8):1089.

47. Jette M, Sidney K, Campbell J. Effects of a 12-Week Walking Program on Maximal and Submaximal Work Output Indexes in Sedentary Middle-Aged Men and Women. J Sports Med Phys Fitness 1988;28(1):59-66.

48. Moreau KL, Degarmo R, Langley J, et al. Increasing daily walking lowers blood pressure in postmenopausal women. Med Sci Sports Exerc 2001;33(11):1825-31.

49. Morgan AL, Tobar DA, Snyder L. Walking toward a new me: the impact of prescribed walking 10,000 steps/day on physical and psychological well-being. J Phys Act Health 2010;7(3):299.

50. Murphy MH, Murtagh EM, Boreham CAG, et al. The effect of a worksite based walking programme on cardiovascular risk in previously sedentary civil servants. BMC Public Health 2006;6(1):136.

51. Murtagh EM, Boreham CAG, Nevill A, et al. The effects of 60 minutes of brisk walking per week, accumulated in two different patterns, on cardiovascular risk. Prev Med 2005;41(1):92-97.

52. Probart CK, Notelovitz M, Martin D, et al. The Effect of Moderate Aerobic Exercise on Physical-Fitness among Women 70 Years and Older. Maturitas 1991;14(1):49-56.

53. Ready AE, Drinkwater DT, Ducas J, et al. Walking Program Reduces Elevated Cholesterol in Women Postmenopause. Can J Cardiol 1995;11(10):905-12.

54. Ready AE, Naimark B, Ducas J, et al. Influence of walking volume on health benefits in women postmenopause. Med Sci Sports Exerc 1996;28(9):1097-105.

55. Santiago MC, Leon AS, Serfass R. Failure of 40 Weeks of Brisk Walking to Alter Blood Lipids in Normolipemic Women. Can J Appl Physiol 1995;20(4):417-28.

56. Serwe KM, Swartz AM, Hart TL, et al. Effectiveness of Long and Short Bout Walking on Increasing Physical Activity in Women. J Womens Health 2011;20(2):247-53. 
57. Woolf-May K, Kearney EM, Owen A, et al. The efficacy of accumulated short bouts versus single daily bouts of brisk walking in improving aerobic fitness and blood lipid profiles. Health Educ Res 1999;14(6):803-15.

58. Zhang J, Chen G, Lu W, et al. Effects of physical exercise on health-related quality of life and blood lipids in perimenopausal women: a randomized placebo-controlled trial. Menopause 2014;21(12):126976.

59. Field A. Discovering statistics using IBM SPSS statistics. 4th ed. Los Angeles: Sage 2012.

60. World Health Organization. Global Recommendations on Physical Activity for Health. Geneva: WHO 2010.

61. Brannan M, Varney J, Timpson C, et al. 10 minutes brisk walking each day in mid-life for health benefits and achievement of recommended activity levels - Evidence summary. London: Public Health England, 2017. 
Figure 1

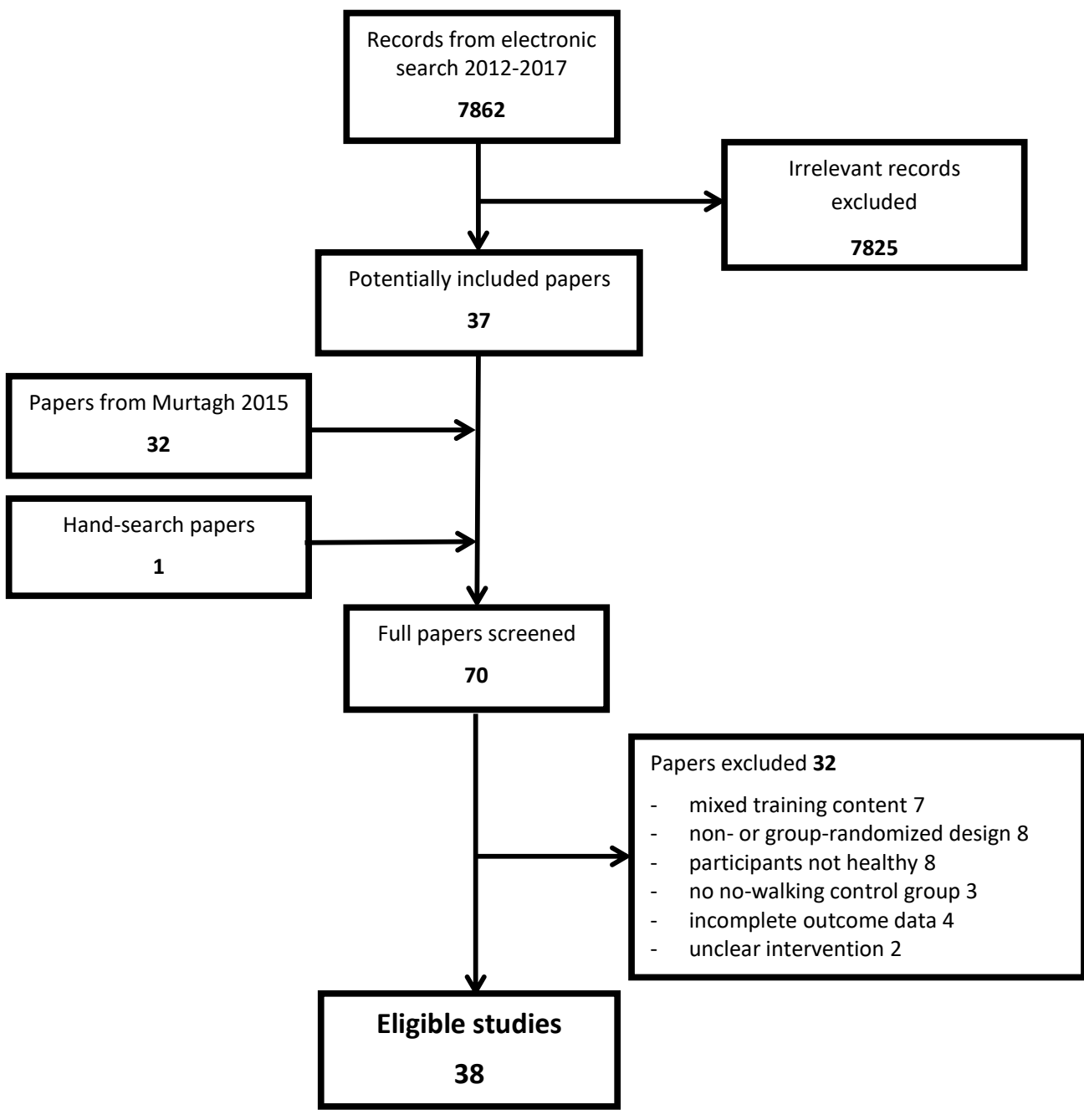


Figure caption: Selection of studies. 